\title{
Design of Mini Generator based on the Principle of Water Flow Pressure by using Vortex Turbine
}

\author{
Sahazati Md Rozali, Rozilawati Mohd Nor, Aliza Che Amran, Saleha Mohamad Saleh
}

\begin{abstract}
In Malaysia, usually an electricity energy is generated based on fuel sources such as coal and natural gases. Since the consumption of electric energy is keep increasing yearly, the extinction of these sources becomes one of the main problems in this industry. Thus, the country needs to spend higher expenditure to import these sources since it has limited quantity and it is not a renewable energy source. In addition, the usage of the coal as sources affect the environment. Therefore, this research proposed a prototype of mini generator based on the principle of water flow pressure. The prototype is developed based on the flow of water vortex that is influenced by gravity and has the capability to generate energy at low-head flat geographically area. A controller for this system is designed by using Arduino. The objective of this research is to study the efficacy of this type of generator since it is one of the techniques to generate electricity. The efficiency of the designed prototype is analyzed based on different radius value of the basin and the effect of different type of motor used to spin the turbine. The results show that the smaller radius of the basin and direct drive motor generate higher voltage if the system is being tested individually. However, if both characteristics are combined together, the highest radius of basin with direct drive motor produced bigger value of voltage.
\end{abstract}

Keywords : Electric generator, water flow pressure, vortex turbine.

\section{INTRODUCTION}

Electrical energy is among the main energy source in daily life either in domestic or commercial usage. In order to drive the development of the country, a good production of electrical supply is crucial aspect that needs a proper monitoring. This energy could be generated by various sources which are renewable as well as non-renewable sources. Nuclear, fuel and natural gas are the examples of non-renewable resources while solar, wind and hydro are the examples of the renewable sources that are used to generate this electrical power. Though non-renewable source is simple to be used, it caused negative impact to the environment and society.

Revised Manuscript Received on Sept 11, 2019.

* Correspondence Author

Sahazati Md Rozali*, Dept of Electrical Engineering Technology, Faculty of Electrical \& Electronic Engineering Technology, Universiti Teknikal Malaysia Melaka, Malaysia. Email: sahazati@utem.edu.my

Rozilawati Mohd Nor, Dept of Electrical Engineering Technology, Faculty of Electrical \& Electronic Engineering Technology, Universiti Teknikal Malaysia Melaka, Malaysia. Email: rozilawati@utem.edu.my

Aliza Che Amran, Dept of Electrical Engineering Technology, Faculty of Electrical \& Electronic Engineering Technology, Universiti Teknikal Malaysia Melaka, Malaysia. Email: aliza@utem.edu.my

Saleha Mohamad Saleh, Dept of Electrical Engineering Technology, Faculty of Electrical \& Electronic Engineering Technology, Universiti Teknikal Malaysia Melaka, Malaysia. Email: saleha@utem.edu.my
Most of the country in the world slowly move the electricity generation to renewable energy resources which are the natural sources. Malaysia also doing the same thing. Previously, our country depends on fuel materials such as coal or natural gases. However, due to the limitation of this sources, the country uses other alternatives such as hydro and wind to produce electric energy. This is because the usage of non-renewable sources involves higher expenditure since the source is extinct and needs to be imported from other country. In addition, the continuous usage of these resources contributes to the environment pollution and affect the community. The information from International Energy Efficiency shows that about $80 \%$ of the total world primary energy in 2014 and 2015 is generated by burning of fossil fuels which increase global greenhouse gas (GHG) emission dramatically [1]. It is expected that the world GHG emission caused by fossil fuel combustion is increased from $54 \mathrm{Gt}$ CO2-eq in 2010 to $70 \mathrm{Gt} \mathrm{CO} 2$-eq in 2050 [2]. This is the main reason the world needs renewable and environmentally friendly energy resources for electricity generation such as hydro, wind and solar.

$71 \%$ of electricity generation around the world comes from hydroelectric generator. In Malaysia, hydro only contributes $11 \%$ of electrical power for daily used. Kenyir Lake and Bakun dam are among the hydroelectric generator in Malaysia. It is function as a reservoir to supply water for domestic usage and also as an electrical generator for our country. This research proposed the development of prototype of mini generator based on the principle of water flow pressure in order to study the effectiveness of this system in our daily usage. A mini water gravitational vortex hydro power is chosen as a design prototype. The performance of the designed system is analyzed by changing the radius of the basin and the type of motor attached to the system.

\section{HYDROELECTRIC GENERATOR}

The water turbine is originated in the nineteenth century and was trusted to be used for industrial power before the appearance of electrical grids. The first usage of production of electric energy based on water flow is a waterwheel on the Fox River in Wisconsin in 1882. A hydraulic turbine operates by converting the energy produced by flowing water into mechanical energy. Then, a hydroelectric generator which operates based on Faraday principles converts this mechanical energy into electricity. Figure 1 illustrates the general operation of this principles. 


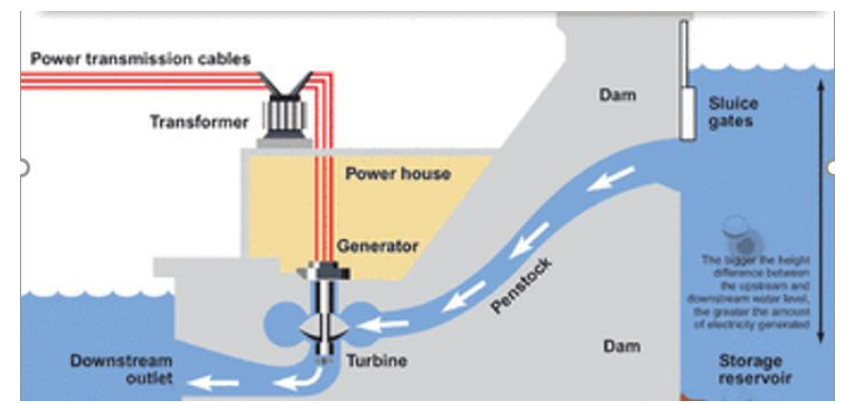

Fig. 1. General operation of hydroelectric generator

Referring to Figure 1, the flow of the water which is being released from the reservoir yields the force through the dam and spins the blades of a turbine which is connected to the generator. This generator produced electricity as it spins. The water flows back into the river on the other side of the dam after passing through the turbine and the process is repeated continuously. In order to ensure the force is strong enough to spin the blades, the flow of water also needs to be strong. Therefore, usually the dam is built in the higher area such that the water flow from higher area into the lower area will produce higher speed and force. Another factor that influence the production of the force is the design form of the turbine.

In Malaysia, hydro is utilized to generate electric on July 1900. It started with a small hydroelectric plant at Sempam River near Raub, Pahang which is built by the Raub-Australian gold mining business. However, this energy is commercially used to supply electricity for domestic usage around 1970s. Although most of the country in the world is moving towards this renewable energy sources, due to limited technology and cost, Malaysia only contribute small scale of producing energy by this method.

Since the turbine is the important part to connect to the generator and produce electricity, a proper decision of this component is required. There are three types of turbine; impulse turbine, reaction turbine and gravity turbine. Impulse turbine driven by a high-velocity water jet of water while a reaction turbine rotates quicker than impulse turbine. The gravity turbine can be driven by just the weight of water entering the turbine and released to the bottom. The vortex turbine that is proposed in this research is a type of gravity turbine. Figure 2 shows the general diagram of vortex turbine.

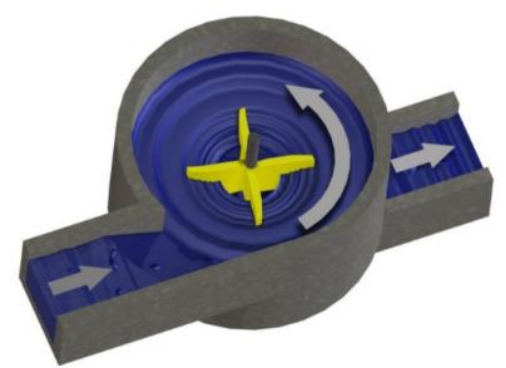

Fig. 2. Vortex turbine

Referring to the figure, the vortex turbine has the capability to produce energy by utilize a low hydraulic head of 0.7 to 3 meters. The principle operation of this type of turbine is based on a circular basin with a central drain. The water passes through a direct inlet and tangentially right into a round basin. It forms a large vortex over the center bottom level drain of the basin. A turbine withdraws rotational energy from the vortex which is converted into electric power by a generator. [3] studied the effect of basin structure of water vortex stream. The research indicates that the depth of water, the orifice diameter and the inlet and basin configuration determine the yielded kinetic energy. It is also discovered that a cylindrical container with an orifice in the middle of the basin with plate might be the best configuration in order to obtain the optimum value of kinetic energy. [4] conducted research on the effect of conical basin compared to conventional cylindrical basin on the production of kinetic energy. The research found that the basin entrance, basin diameter, notch length, canal height and cone angle affect the production of kinetic energy by vortex turbine. [3] developed the model of water vortex turbine which is applied in a minimal head pico hydro power plant. The study figures out that outlet diameter at the bottom centre of the basin, gravitational vortex head and flow rate affect the velocity vector stream. Based on the experiment done in this research, the outlet diameter less than $0.20 \mathrm{~m}$ failed to supply enough torque to overcome mechanical friction and electric load of the system.

According to [5] the turbine is the main element that influence the performance of water vortex hydropower. This is because it is located at the center straightened to the central outlet of the basin and being pressured by the water flow. [6] claims that helical turbine techniques with hydrofoil profile will produce good water stream in the gravitational vortex. The Francis turbine techniques also might be used in order to increase the speed of the water flow. This is because, huge variation along the peripheral velocity of the blade is important in order to twist the blade. Another research has been done in order to observe the effect of blade's number and blade's radius on the performance of the turbine. Subash Dhakal et al shows that the best position of the turbine is the bottom part of the basin. The increment of basin's depth will increase the water velocity. Besides, a smaller number of blades' radius also increase the effectiveness of the turbine since the frictional in the internal surface of the basin is reduced. [7] also discovered that the vortex power in conical basin is more than cylindrical basin.

[6] executed experiments on vortex turbine power plant by using three different turbines and mounted it at different heights in the conical basin. The study found that the utmost energy is harvested if the turbine is installed closed to the outlet of the basin. [8] also produced electricity through the use of artificial vortex power generator which includes eight inverted cone design blades. The prototype succeeded to produce more than $150 \mathrm{~W}$ of electricity. [9] aim to study the consequence of turbine materials in power generation performance based on the water free vortex hydro power plant made of steel and aluminium. These turbines contain five blades and had been twisted with angles along the elevation of water. It had been found that the low flow rate affected a velocity of aluminium turbine rotation more than steel turbine. Although hydropower plant produces zero air emissions, it affects the quality of water, the habitat of wildlife and disturb the fish migration. The gravitational water vortex power system which is classified as pico hydropower offers a solution involving this environmental problem. The advantages of using an induced vortex above gravityaccelerated water are increase the efficiency, reduce the cost and escalates the sustainability of the river [10]. 
This research proposed the prototype of mini water gravitational vortex hydropower system. A controller for the designed system is developed by using Arduino. The efficiency analysis of the prototype is done by observing the different radius value of the basin and the effect of different type of motor used to spin the turbine.

\section{METHODOLOGY}

The development process is started with the software part followed by the hardware part. The software part involved the usage of solid work. Then the drawing structure is built in hardware part and the controller is designed by using arduino. The prototype of mini water vortex hydropower system is designed by using solid work. The design consider that the high flow rate will be produced such that high voltage will be generated. The outlet basin is chosen at $0.1 \mathrm{~m}$ in order to build vortex form. Figure 3 shows the drawing structure designed by solid work.

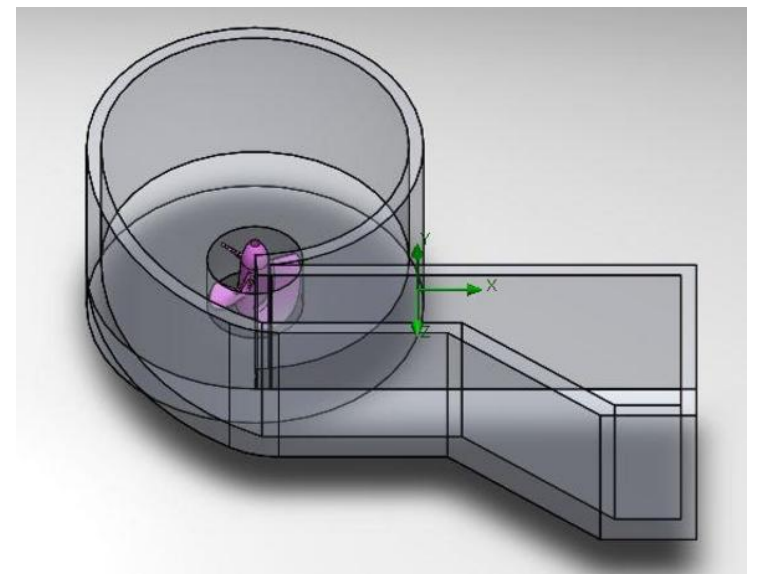

Fig. 3. The drawing structure of Water Vortex Hydro

The components involved in the developing of this prototype are the turbine, motor, flow meter, AC- DC rectifier, arduino uno and LCD keypad shield. The turbine is located at the outlet part of the system. The motor converts motion energy into electrical power to be used in an external circuit while the flow meter is used to show the velocity of the water that flowing through the piping with different length. This project used an ac to dc converter circuit which will generate $12 \mathrm{~V}$ supply based on the current produced by the generator and this circuit is called as a rectifier. Figure 4 and 5 respectively illustrates the side view and the top view of gravitational water vortex power plant.

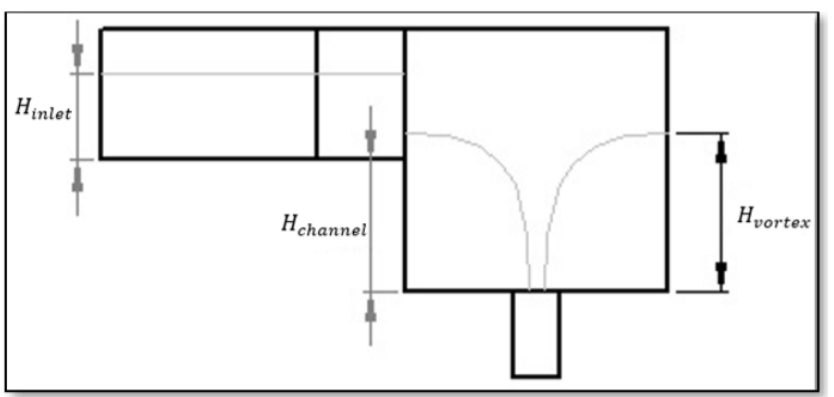

Fig. 4. Gravitational Water Vortex Power Plant side view



Fig. 5. Gravitational Water Vortex Power Plant top view The controller of the whole system is developed by using Arduino Uno. The reading of the generated voltage is displayed on LCD keypad shield.

\section{RESULTS AND DISCUSSION}

The performance of the designed prototype is analyzed based on the different radius value of the basin and the effect of different type of motor used to spin the turbine. Figure 6 shows the cylindrical basin with three different radius which are $10 \mathrm{~mm}, 20 \mathrm{~mm}$ and $30 \mathrm{~mm}$ while Table 1 list down the flow rate and generated voltage by each different basin.

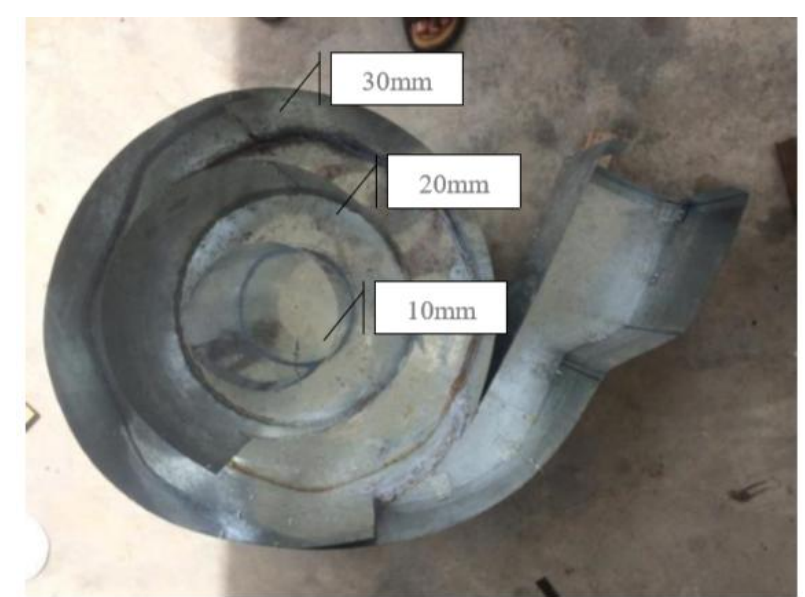

Fig. 6. Basin with radius $10 \mathrm{~mm}, 20 \mathrm{~mm}$ and $30 \mathrm{~mm}$

Table 1. Flow rate and generated voltage by different radius of basin

\begin{tabular}{|l|l|l|l|l|}
\hline $\begin{array}{l}\text { Structural } \\
\text { Design WVH }\end{array}$ & Radius ( mm ) & $\begin{array}{l}\text { Initial Flow } \\
\text { rate ( L/min })\end{array}$ & $\begin{array}{l}\text { Outlet Flow } \\
\text { Rate ( L/min ) }\end{array}$ & Voltage ( V ) \\
\hline \multirow{3}{*}{ Cylindrical } & 10 & 3.44 & 12.5 & 2.1 \\
\cline { 2 - 5 } & 20 & 3.43 & 20.3 & 2.3 \\
\cline { 2 - 5 } & 30 & 3.44 & 2.89 & 1.3 \\
\hline
\end{tabular}

By referring to Table 1, the basin with radius $10 \mathrm{~mm}$ generates 2.1 Volt since the flow rate is lower. The basin with $20 \mathrm{~mm}$ radius produced highest voltage value at 2.3 Volt with highest outlet flow rate at $20.3 \mathrm{~L} / \mathrm{min}$. Thus, the optimum radius value is $20 \mathrm{~mm}$ for this type of basin in order to produce highest voltage since the size of basin is suitable to accept lower value of inlet flow and produce highest outlet flow rate compared to the two others. Three different types of motor have been tested on this prototype to observe the effectiveness of voltage generation. They are induction motor with permanent magnet, induction motor without permanent magnet and direct drive motor. 
Table 2 display the type of motor used for this prototype and the value of voltage generated.

Table 2. The generated voltage by different type of motor used

\begin{tabular}{|l|c|}
\hline \multicolumn{1}{|c|}{ Type of motor } & Voltage, $\mathbf{V}$ \\
\hline $\begin{array}{l}\text { Induction motor with } \\
\text { permanent magnet }\end{array}$ & 2.1 \\
\hline $\begin{array}{l}\text { Induction motor without } \\
\text { permanent magnet }\end{array}$ & 0.04 \\
\hline Direct drive motor & 12 \\
\hline
\end{tabular}

Based on Table 2, the prototype with direct drive motor produced highest voltage compared to the other two types of motor.

\section{CONCLUSION}

A prototype of mini generator based on the principle of water flow pressure is developed in this research as a simple benchmark to study the effectiveness of higher design of this system later. Based on the operation of this prototype of the system, two criterions have been analyzed which affect the performance of the designed system. The radius of the basin and the type of motor used influence the value of the voltage generated by the prototype. If only the basin radius is considered, $20 \mathrm{~mm}$ basin radius produced highest voltage at $2.3 \mathrm{~V}$ with outlet flow rate at $20.3 \mathrm{~L} / \mathrm{min}$. However, when the basin is attached to the motor, a prototype with $30 \mathrm{~mm}$ basin's radius with direct drive motor attached to it produced highest voltage value at $12 \mathrm{~V}$.

\section{ACKNOWLEDGMENT}

This project is the pre-requisite to the grading of course Bachelor of Electrical Engineering Technology (Automation $\&$ Robotics) [BEEA] in the Faculty of Engineering Technology. This work was supported in part by UTeM under Grant Nos PJP/2018/FTK(17C)/S01643.

\section{REFERENCES}

1. M. Hossain, S. Mekhilef, M. Danesh, L. Olatomiwa, S. Shamshirband, "Application of Extreme Learning Machine for Short Term Output Power Forecasting of Three Grid Connected PV Systems", Journal of Cleaner Production, Vol 167, 2017, pp 395-405.

2. M.S. Uddin, S. Kumar, "Energy, Emissions and Environmental Impact Analysis of Wind Turbine Using Life Cycle Assessment Technique", Journal of Cleaner Production, Vol 69, 2015, pp 153-164.

3. Wanchat, Suntivarakorn, Wanchat, Tonmit, \& Kayanyiem, 2013, A Parametric Study of A Gravitation Vortex Power Plant, Advanced Materials Research, Vol. 805-806, 2013, pp 811-817

4. Sagar Dhakal, Ashesh B. Timilsina, Rabin Dhakal, Dinesh Fuyal, Tri R Bajracharya, Hari P. Pandit, Nagendra Amatya, Amrit M. Nakarmi, Comparison of cylindrical and conical basins with optimum position of runner: Gravitational water vortex power plant, Renewable and Sustainable Energy Reviews, Vol. 48, 2015, pp 662-669

5. M. M. Rahman, J. H. Tan, M. T. Fadzlita, A. R. Wan Khairul Muzammil, A Review on the Development of Gravitational Water Vortex Power Plant as Alternative Renewable Energy Resources, International Conference on Materials Technology and Energy, 2017.

6. Marian Marius-Gheorghe, A, Sajin Tudor,B And Azzouz Abdelkrim, Study Of Micro Hydropower Plant Operating In Gravitational Vortex Flow Mode, Applied Mechanics And Materials. Vol. 371, 2013, pp 601-605

7. Subash Dhakal, Sushan Nakarmi, Arun Thapa, Pikam Pun, Development and Testing of Runner and Conical Basin for Gravitational Water Vortex Power Plant, Book Chapter of Research Book Series Energy System Planning and Analysis, Center for Energy Studies (CES), Institute of Engineering, Tribhuvan University, Nepal, 2014
8. Aravind Venukumar, Artificial Vortex $(\mathrm{ArVo})$ Power Generation - An innovative micro hydroelectric power generation scheme, Proceedings of 2013 IEEE Global Humanitarian Technology Conference: South Asia Satellite (GHTC-SAS), 23-24 Aug. 2013, Trivandrum, India

9. P Sritram, W Treedet and R Suntivarakorn, Effect of turbine materials on power generation efficiency from free water vortex hydro power plant, IOP Conf. Series: Materials Science and Engineering 103 (2015) 012018, 4th Global Conference on Materials Science and Engineering (CMSE 2015), pp 1-7

10. O. B. Yaakoba, Yasser M. Ahmeda,b*, A. H. Elbatrana , H. M. Shabara, A Review on Micro Hydro Gravitational Vortex Power and Turbine Systems, Jurnal Teknologi UTM, Vol 69:7, 2014, pp 1-7

\section{AUTHORS PROFILE}



Sahazati binti Md Rozali was born in Melaka on $19^{\text {th }}$ February 1981.She received her degree in Bachelor of Electrical \& Electronic Engineering (Electronic) in 2004 from Universiti Sains Malaysia. Then she pursued her Master in Electrical Engineering (Control,Automation \& Robotics) in Universiti Teknologi Malaysia on 2006 and Doctor of Philosophy in Electrical Engineering from the same university in 2014. She is a member of Board of Engineers Malaysia (BEM) and Malaysian Board of Technologist (MBOT). Her specialization is in control system, modelling and system identification.

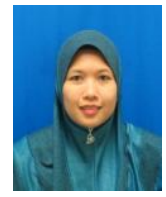

Rozilawati binti Mohd Nor was born in Miri, Sarawak on $27^{\text {th }}$ May 1988. She finished her first degree in Bachelor of Electrical Engineering (Control, Instrumentation \& Automation) on 2011 then completed her Master of Science in Electrical Engineering on 2015 at Universiti Teknikal Malaysia Melaka. Now she is lecturer at Faculty of Electrical and Electronic Engineering Technology, Universiti Teknikal Malaysia Melaka. Her major field of study is in control system and most of her publications are in control system design and application. She is a member of Board of Engineers Malaysia (BEM) and Malaysian Board of Technologist (MBOT)



Aliza binti Che Amran was born in Kuala Lumpur Malaysia on 17th April 1980. She finished her first degree in Bachelor of Electrical and Electronics Engineering (Control, Instrumentation \& Automation) on 2003 at Universiti Teknologi Petronas, Perak. She then completed her Master of Electrical and Computer Systems Engineering on 2005 at Monash University, Melbourne. In 2013, she completed her Doctoral studies from Yokohama National University, Japan on biped robot walking. Now she is a senior lecturer at Faculty of Electrical and Electronic Engineering Technology, Universiti Teknikal Malaysia Melaka. Her research work is mainly in control system, robotics, and TVET. She is a member of Board of Engineers Malaysia (BEM) and Malaysian Board of Technologist (MBOT).

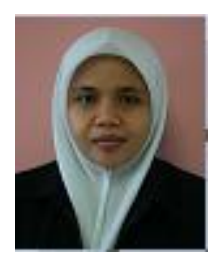

Saleha Mohamad Saleh is born on $5^{\text {th }}$ October 1975 at Melaka, Malaysia and got her first degree in Electrical Engineering (Communication) at Universiti Teknologi MARA on 2000 followed by Master in Electrical Engineering (Mechatronics and Automatic Control) in Electrical Engineering at Universiti Teknologi Malaysia on 2006. Her major field of study is in Control System and Instrumentation

Her previous research includes Implementation of MRAC, SVMPC and PID Control Based on Direct Digital Control Application for DC Servomotor, Electromyography Signal Analysis based on Time Frequency Distribution for Industrial Application, Computer Vision and Digital Signal Processing Saleha is a member of Board of Engineer Malaysia (BEM) and Malaysian Board of Technologist (MBOT). Currently, she is a lecturer at Faculty of Electrical and Electronic Engineering Technology, Universiti Teknikal Malaysia Melaka. 